МАРІЯ РЕДЬКІНА, старший викладач кафедри фізичного виховання і спорту, Національний педагогічний університет імені М.П. Драгоманова, Україна ORCID ID 0000-0001-8482-2594 rmadniprowood@gmail.com

\title{
ОСОБЛИВОСТІ МЕТОДИКИ ВИЗНАЧЕННЯ ІНДИВІДУАЛЬНОЇ РУХОВОЇ АКТИВНОСТІ СТУДЕНТІВ ТА ЇЇ ВПЛИВ НА ПСИХОФІЗИЧНИЙ СТАН
}

\author{
MARIIA REDKINA, Senior Lecturer of the Department of \\ Physical Education and Sports, National Pedagogical \\ Dragomanov University, Ukraine
}

\section{PECULIARITIES OF METHODS OF DETERMINATION OF INDIVIDUAL MOTOR ACTIVITY AND ITS INFLUENCE ON PSYCHOPHYSICAL STATUS OF STUDENTS}

\begin{abstract}
У зв'язку з постійним розвитком інформаційно-комунікаційних технологій сучасна молодь веде малорухливий спосіб життя, що призводить до зниження рівня рухової активності у студентів закладів вищої освіти, і як наслідок, спостерігається високий рівень захворюваності.

Ураховуючи стрімкий розвиток науково-технічного прогресу, нами розроблено методику визначення індивідуальної рухової активності з використанням інфокомунікаційних технологій.

У статті охарактеризовано психофізичний стан студентів контрольної та експериментальної груп після впровадження запропонованої методики в освітній процес 3 фізичного виховання.
\end{abstract}

Ключові слова: психофізичний стан, рухова активність, студенти, фізичне виховання, здоров'я.

Summary. Due to the constant development of information and communication technologies, modern youth lead a sedentary lifestyle, which leads to a decrease in the level of motor activity in students of higher education institutions, and as a

(с) М. Редькіна consequence, a high level of morbidity is observed.

Given the rapid development of scientific and technological progress, we have developed a method of determining individual motor activity using information and communication technologies.

The article describes the psychophysical state of the students of the control and experimental groups after the introduction of the proposed methodology in the educational process of physical education.

Key words: psychophysical state, physical activity, students, physical education, health.

Мета: охарактеризувати динаміку змін показників психофізичного стану студентів, які використовували програму для визначення рівня рухової активності.

Постановка проблеми в загальному вигляді. Основний підхід до проблеми управління руховою активністю базується на положеннях про те, що завдання і зміст процесу фізичного виховання до трудової діяльності повинні відповідати сучасним вимогам. Науково-технічний прогрес істотно перетворює умови, у яких ми знаходимося, змінюється темп життя, молодь більше веде малорухливий спосіб життя, що негативно позначається на стані їхнього здоров'я. Адже загальновідомий взаємозв'язок рухової активності із психофізичними станом; чим нижчий рівень рухової активності, тим нижчий рівень здоров'ї, тим гірший психоемоційний стан (Бальсевич, 1990).

Інфокомунікаційні впровадження стосуються не тільки галузі фізичного виховання, а й інших сфер життя, а механізація, автоматизація і пов'язана 3 цим інтенсифікація праці на виробництві та в побуті вимагають саме більше розумової діяльності. Крім того, системоутворювальним початком структури психофізичного стану виступає його взаємозв'язок з руховою активністю, що характеризує i фізичну, і функціональну підготовленість, фізичний розвиток, психічні процеси, здатність до управління руховими діями (3aхаріна, 2007).

Аналіз досліджень і публікацій. У сучасних працях учених досить широко розглянуто питання виміру та оцінки режиму рухової активності студентів, досліджено добовий та тижневий обсяги рухової активності осіб різного віку і фізичного стану за допомогою вико- 
Показники емоційного стану студентів I курсу до та після педагогічного експерименту

\begin{tabular}{|c|c|c|c|c|c|}
\hline $\begin{array}{c}\text { Показники } \\
\text { емоційного стану }\end{array}$ & Групи & $\begin{array}{r}\bar{X} \\
\text { До експерименту }\end{array}$ & $\begin{array}{cc}\bar{x} & \\
\quad \text { Після } \\
\text { експерименту }\end{array}$ & $\begin{array}{l}\text { \% приріст } \\
\text { показника }\end{array}$ & $\mathrm{P}$ \\
\hline \multicolumn{6}{|c|}{ Хлопці } \\
\hline \multirow{2}{*}{ Самопочуття } & $\mathrm{K}$ & 3,7 & 3,8 & $1,7 \%$ & $\mathrm{p} ? 0,05$ \\
\hline & $\mathrm{E}$ & 3,6 & 4,2 & $18,5 \%$ & $\mathrm{p} ? 0,05$ \\
\hline \multirow{2}{*}{ Активність } & $\bar{K}$ & 4,1 & 4,2 & $2,1 \%$ & $\mathrm{p} ? 0,05$ \\
\hline & E & 4,0 & 4,8 & $8,6 \%$ & $\mathrm{p} ? 0,05$ \\
\hline \multirow{2}{*}{ Настрій } & $\mathrm{K}$ & 3,5 & 3,8 & $2,6 \%$ & $\mathrm{p} ? 0,05$ \\
\hline & $\mathrm{E}$ & 3,2 & 4,9 & $25,1 \%$ & $\mathrm{p} ? 0,05$ \\
\hline \multicolumn{6}{|c|}{ Дів чата } \\
\hline \multirow{2}{*}{ Самопочуття } & $\mathrm{K}$ & 3,3 & 3,6 & $1,8 \%$ & $\mathrm{p} ? 0,05$ \\
\hline & $\mathrm{E}$ & 3,1 & 4,2 & $22,7 \%$ & $\mathrm{p} ? 0,05$ \\
\hline \multirow{2}{*}{ Активність } & K & 3,1 & 3,2 & $1,5 \%$ & $\mathrm{p} ? 0,05$ \\
\hline & $\mathrm{E}$ & 3,0 & 4,8 & $31,6 \%$ & $\mathrm{p} ? 0,05$ \\
\hline \multirow{2}{*}{ Настрій } & $\mathrm{K}$ & 3,5 & 3,7 & $2,7 \%$ & $\mathrm{p} ? 0,05$ \\
\hline & $E$ & 3,7 & 4,5 & $21,3 \%$ & $\mathrm{p} ? 0,05$ \\
\hline
\end{tabular}

ристання Фремінгемської методики. Так, закономірності i взаємозв'язки рухової активності та фізичного стану вивчали О. Пирогова, Л. Іващенко, А. Драчук, О. Куц, Т. Круцевич, Л. Хрипко. Однак учені робили більший акцент на професійно-прикладні; вікові і статеві аспекти, різні за змістом види фізкультурно-спортивної та оздоровчої активності.

Аналіз літературних джерел
(Волков, 2001; Захаріна, 2007; Носко, 2000) показав, що, незважаючи на ряд досліджень у галузі фізичного виховання, досі актуальним залишається питання впливу рухової активності на психофізичний стан людини. Адже на даний час не визначено єдиної концепції обсягу й інтенсивності фізичних навантажень, які позитивно впливали б на рівень фізичного здоров'я та покращували психоемоційний стан сучасної молоді (Балбенко, 2008).

Тому з метою залучення молоді до більш активної рухової діяльності, мотивації їх до занять $з$ фізичного виховання нами розроблено й упроваджено у процес фізичного виховання методику визначення індивідуальної рухової активності 3 використанням інформаційнокомунікаційних технологій.

Виклад основного матері-

Таблиия 2

Динаміка показників фізичного здоро в'я студентів I курсу в умовах педагогічного експерименту

\begin{tabular}{|c|c|c|c|c|c|}
\hline \multirow[b]{2}{*}{ Функціо нальні інд екси } & \multirow[b]{2}{*}{ Групи } & \multicolumn{2}{|c|}{$\bar{X} \pm \mathrm{m} \bar{x}$} & \multirow{2}{*}{$\begin{array}{l}\text { \% приріст } \\
\text { показника }\end{array}$} & \multirow{2}{*}{$\mathrm{p}$} \\
\hline & & До експерименту & $\begin{array}{c}\text { Після } \\
\text { експерименту }\end{array}$ & & \\
\hline \multicolumn{6}{|c|}{ Хлопщі } \\
\hline \multirow{2}{*}{$\begin{array}{l}\text { Ваго-ростовий індекс, } \\
\kappa г / \mathrm{M}^{2}\end{array}$} & K & $22,8 \pm 2,5$ & $22,9 \pm 2,1$ & 0,4 & $\mathrm{p} ? 0,05$ \\
\hline & $\mathrm{E}$ & $22,2 \pm 1,4$ & $23,5 \pm 2,3$ & 1,6 & $\mathrm{p} ? 0,05$ \\
\hline \multirow{2}{*}{$\begin{array}{l}\text { Життє вий } \\
\text { мл/кг }\end{array}$} & K & $47,2 \pm 14,4$ & $48,8 \pm 3,3$ & 2,1 & $\mathrm{p} ? 0,05$ \\
\hline & $\mathrm{E}$ & $48,5 \pm 3,5$ & $59,3 \pm 4,1$ & 18,1 & $\mathrm{p} ? 0,05$ \\
\hline \multirow[t]{2}{*}{ Силовий індекс, \% } & $\mathrm{K}$ & $60,8 \pm 13,1$ & $62,1 \pm 8,3$ & 1,7 & $\mathrm{p} ? 0,05$ \\
\hline & $\mathrm{E}$ & $42,4 \pm 9,2$ & $55,5 \pm 8,1$ & 24,6 & $\mathrm{p} ? 0,05$ \\
\hline \multirow[t]{2}{*}{ Проба Руф’є, ум. од. } & $\mathrm{K}$ & $9,5 \pm 4,0$ & $9,8 \pm 2,9$ & 0,9 & $\mathrm{p} ? 0,05$ \\
\hline & $\mathrm{E}$ & $10,7 \pm 1,8$ & $8,6 \pm 3,1$ & 2,3 & $\mathrm{p} ? 0,05$ \\
\hline \multicolumn{6}{|c|}{ Дівчат а } \\
\hline \multirow{2}{*}{$\begin{array}{l}\text { Ваго-ростовий індекс, } \\
\kappa г / \mathrm{M}^{2}\end{array}$} & $\mathrm{~K}$ & $22,9 \pm 2,1$ & $23,1 \pm 2,3$ & 0,4 & $\mathrm{p} ? 0,05$ \\
\hline & $\bar{E}$ & $21,1 \pm 1,8$ & $25,3 \pm 3,1$ & 2,8 & $\mathrm{p} ? 0,05$ \\
\hline \multirow{2}{*}{$\begin{array}{l}\text { Життєвий індекс, } \\
\text { мл/кг }\end{array}$} & K & $48,2 \pm 5,4$ & $49,9 \pm 3,1$ & 1,1 & $\mathrm{p} ? 0,05$ \\
\hline & $\mathrm{E}$ & $47,4 \pm 4,5$ & $54,2 \pm 3,7$ & 22,6 & $\mathrm{p} ? 0,05$ \\
\hline \multirow[t]{2}{*}{ Силовий індекс, \% } & K & $39,0 \pm 6,6$ & $39,1 \pm 5,6$ & 0,2 & $\mathrm{p} ? 0,05$ \\
\hline & $\mathrm{E}$ & $39,6 \pm 6,2$ & $51,6 \pm 7,8$ & 26,1 & $\mathrm{p} ? 0,05$ \\
\hline \multirow[t]{2}{*}{ проба Руф’є, ум.од. } & $\mathrm{K}$ & $11,0 \pm 3,5$ & $10,9 \pm 1,3$ & 2,6 & $\mathrm{p} ? 0,05$ \\
\hline & $\mathrm{E}$ & $12,3 \pm 3,1$ & $10,1 \pm 2,1$ & 4,2 & $\mathrm{p} ? 0,05$ \\
\hline
\end{tabular}


алу дослідження. Для експериментальної перевірки ефективності запропонованої методики визначення індивідуальної рухової активності студентів ¥іi було впроваджено в освітній процес фізичного виховання. Це дозволяє молоді оперувати показниками свого фізичного стану, визначати належний рівень рухової активності, виходячи 3 власних даних, складати свою програму рухової активності відповідно до бажаного рівня фізичного стану, обирати найбільш оптимальні параметри фізичних навантажень.

Крім того, студенти матимуть змогу у звичайних гаджетах вирахувати кількість витрачених калорій та загальний час тренувань (в одиницях часу, відстані, ваги тощо), оцінити власну пульсову криву під час рухової активності, а також достатність виконаних фізичних навантажень і рухової активності загалом.

Так, у результаті впровадження зазначеної вище методики у студентів експериментованої групи зафіксовано позитивні зміни у психофізичних показниках, покращенні самопочуття. Крім того, розроблена методика покращила рівень мотивації та підвищила добову рухову активність студентів (табл. 1-2).

3'ясовано, що середньостатистичні результати самопочуття, настрою i активності у хлопців I курсу контрольної групи (далі - КГ) покращились на $1,7 \%, 2,1 \%, 2,6 \%$ відповідно при $\mathrm{p}=0,05$, у хлопців ЕГ дані показники значно покращилися на $18,5 \%, 8,6 \%$ та $25,1 \%$ відповідно при $\mathrm{p}=0,05 . \mathrm{У}$ дівчат I курсу при повторному проведенні опитування ми отримали наступні результати: у контрольній групі самопочуття $1,8 \%$, активність - 1,5\%, настрій $-2,7 \%$ при $\mathrm{p}=0,05$; дівчата ЕГ продемонстрували значно кращі результати $22,7 \%, 31,6 \%, 21,3 \%$ відповідно при $\mathrm{p}=0,05$.

Так, показники фізичного здоров'я студентів I курсу у процесі проведення формувального експерименту показали статично достовірні зміни в осіб ЕГ, тоді як динаміка показників фізичного здоров'я молоді КГ позитивна, але недостовірна. Зокрема, у хлопців та дівчат КГ у результаті проведення занять 3 фізичного виховання за загальноприйнятою програмою показники ваго-ростового індексу як у хлопців, так і у дівчат покращилися на $0,4 \%$ при $\mathrm{p}=0,05$; показники життєвого індексу - 2,1\% та $1,1 \%$ відповідно при $\mathrm{p}=0,05$; силовий індекс у хлопців складає $1,7 \%$, у дівчат - 0,2 при р?0,05; результати проби Руф'є у хлопців покращилися на $0,9 \%$, у дівчат - на 2,6\% при р=0,05.

У хлопців та дівчат ЕГ, котрі займалися за впровадженою методикою, показники ваго-ростового індексу покращилися на $1,6 \%$ та 2,8\% відповідно при $\mathrm{p}=0,05$; показники життевого індексу у хлопців підвищилися на $18,1 \%$, у дівчат $-22,6 \%$ при $\mathrm{p}=0,05 ;$ силовий індекс у хлопців - $24,6 \%$, у дівчат $26,1 \%$ при $p=0,05$; показники проби Руф'є у хлопців становлять $2,3 \%$, у дівчат - 4,2\% при $\mathrm{p}=0,05$. Крім того, спостерігалось покращення мотивації до занять $з$ фізичного виховання та рівня рухової активності.

Отже, кількість студентів, котрі виявлять позитивне ставлення до занять фізичними вправами та регулярно їх відвідують на I курсі до початку експерименту становила $54,5 \%$ хлопців та $67,1 \%$ дівчат; після впровадження методики показники значно покращилися: $75,2 \%$ хлопців та $82,5 \%$ вважають зміст фізичного виховання цікавим і позитивно сприймають обов'язкові заняття 3 фізичного виховання, займаються за власною програмою рухової активності, складеною за допомогою комп'ютерної програми.

Якщо ж проаналізувати рівні рухової активності молоді, то після експерименту цей показник у дівчат покращився на $30,2 \%$, а у хлопців - на $35,6 \%$. Таким чином, індекс фізичної активності за добу у хлопців 3 25,4 збільшився до 38,5 балів, а у дівчат до початку експерименту становив 26,8 балів, після - 39,5 балів.
Отож маємо можливість потвердити - ефективність запропонованої методики визначення індивідуальної рухової активності студентів з використанням інформаційно-комунікаційних технологій, яка має позитивний вплив не тільки на психофізичний стан тих, хто займається, а й значно підвищує рівень рухової активності та мотивацію до занять 3 фізичного виховання.

Висновки та перспективи подальших досліджень. Отже, середньостатистичні показники суб'єктивної оцінки емоційного стану та фізичного здоров'я в кінці педагогічного експерименту як у хлопців, так i дівчат експериметальної групи статистично достовірно покращилися на відміну від досліджуваних осіб контрольної групи.

Тому результати проведеного педагогічного дослідження, дозволяють стверджувати про ефективність упровадженої методики визначення інидивідуальньго рівня рухової активності 3 викристанням IКТ, яка позитивно впливає на покращення психофізичних показників та емоційний стан студентів, а це, у свою чергу, підвищує і рухову активність активність, і мотивацію до занять 3 фізичного виховання, сприяє зменшенню захворюваності серед молоді.

Удосконалення методики визначення індивідуальної рухової активності та застосування іiі у процесі фізичного виховання як у закладах вищої освіти, так і у закладах загальної середньої освіти потребують вивчення, що і стане підгрунтям нашого перспективного вивчення.

\section{СПИСОК ЛІТЕРАТУРИ}

Балбенко, С. Ю. (2008). Виховання в студентів інтересу до занять фізичною культурою. Фізичне виховання дітей $і$ молодi.

Бальсевич, В. К. (1990). Физическая подготовка в системе воспитания культуры здорового образа жизни человека. Teория и практика физической культуры, 1, 22-27. 
Волков, В. Ю. (2001). Компьютерные технологи в физической культуре, оздоровительной деятельности и образовательном процессе. Теория и практика физической культуры, 4, $60-63 ; 5,56$.

Захаріна, E. А. (2007). Розробка й обгрунтування експериментальної програми з фізичного виховання для студентів. Теорія і методика фізичного виховання $i$ спорту.

Носко, Н. А., Кривенко А. П. (2000). Вплив занять фізичною культурою на стан здоров'я та фізичну підготовленість студентської молоді. Педагогіка, nсихологія та медико-біологічні проблеми фізичного виховання i cnopmy, 22, 14-18.

Griban, G., Tymoshenko, O., Arefiev, V., Sushchenko, L., Domina, Zh., Malechko, T., Zhuravlov, I., Tkachenko, P., Baldetskiy, A., Prontenko, K. (2020). The role of physical education in improving the health status of students of special medical groups. Wiadomosci Lekarskie, 73 (3), 534-540. Doi $10.36740 /$ W Lek202003125. https://wiadlek.pl/03-2020/.

Arefiev, V., Tymoshenko, O., Domina, Zh., Malechko, T., Arefieva, L., Pliushchakova, O., Dzenzeliuk, D., Dovgan, N., Griban, G., Prontenko, K. (2019). Differentiated approach to physical education of adolescent students. Revista Dilemas Contemporaneos: Educacion, Politica y Valores, VII, 15. Retrieved from https:// dilemas - contemporan eos educacio.webnode.es/files/ $200006421-194 \mathrm{dd} 1 \overline{9} 4 \mathrm{df} /$ E E $19.12 .15 \% 20$ E n fo que $\% 20$ diferenciado $\% 20$ de $\% 201 \mathrm{a} \%$ 20 educaci $\%$ C $3 \%$ B 3 n $\% 20$ f $\%$ C $3 \%$ ADsica $\% 20$ de.....pdf

\section{REFERENCES}

Balbenko, S. Yu. (2008). Education for students of interest to physical education. Physical education of children and youth.

Balsevich, V. (1990). Physical training in the system of education of a healthy lifestyle of a person. Theory and practice of physical culture, 1, 22-27.

Volkov, V. Yu. (2001) Computer technologists in physical culture, recreational activities and educational process. Theory and practice of physical culture, 4, 60-63; 5, 56.

Zaharina, Ye. A. (2007). Development and substantiation of the experimental program of physical education for students. The theory and method of physics. education and sports.

Nosko, N. A., Krivenko, A. P. (2000). The influence of physical culture on the state of health and physical preparedness of student youth. Pedagogics, Psychology and Medical and Biological Problems of Physical Education and Sports, 22, 14-18. Griban, G., Tymoshenko, O., Arefiev, V., Sushchenko, L., Domina, Zh., Malechko, T., Zhuravlov, I., Tkachenko, P., Baldetskiy, A., Prontenko, K. (2020). The role of physical education in improving the health status of students of special medical groups. Wiadomosci Lekarskie, 73 (3), 534-540. Doi $10.36740 / \mathrm{WLek} 202003125$. https://wiadlek.pl/03-2020/.

Arefiev, V., Tymoshenko, O., Domina, Zh., Malechko, T., Arefieva, L., Pliushchakova, O., Dzenzeliuk, D., Dovgan, N., Griban, G., Prontenko, K. (2019). Differentiated approach to physical education of adolescent students. Revista Dilemas Contemporaneos: Educacion, Politica y Valores, VII, 15. Retrieved from https:// dilemas - contem poran eos educacio.webnode.es/_files/ $200006421-194 \mathrm{dd} 194 \mathrm{df} /$ E E $19.12 .15 \% 20 \mathrm{En} \mathrm{fo}$ que $\% 20$ diferenciado $\% 20 \mathrm{de} \% 201 \mathrm{a} \%$ 20 ed ucaci $\%$ C $3 \%$ B 3 n \% 20 f $\%$ C $3 \%$ ADsica $\% 20$ de.....pdf

Стаття надійшла 27.02.2020 p. 